\title{
External Validation of Model-Based Dosing Guidelines for Vancomycin, Gentamicin, and Tobramycin in Critically III Neonates and Children: A Pragmatic Two-Center Study
}

\author{
Stan J. F. Hartman ${ }^{1} \cdot$ Lynn B. Orriëns $^{1} \cdot$ Samanta M. Zwaag ${ }^{1} \cdot$ Tim Poel $^{1} \cdot$ Marika de Hoop $^{2,4} \cdot$ Saskia N. de Wildt $^{1,3,4}$ (I)
}

Published online: 8 June 2020

(c) The Author(s) 2020

\begin{abstract}
Background The Dutch Pediatric Formulary (DPF) increasingly bases its guidelines on model-based dosing simulations from pharmacokinetic studies. This resulted in nationwide dose changes for vancomycin, gentamicin, and tobramycin in 2015. Objective We aimed to evaluate target attainment of these altered, model-based doses in critically ill neonates and children. Methods This was a retrospective cohort study in neonatal intensive care unit (NICU) and pediatric ICU (PICU) patients receiving vancomycin, gentamicin, or tobramycin between January 2015 and March 2017 in two university hospitals. The first therapeutic drug monitoring concentration for each patient was collected, as was clinical and dosing information. Vancomycin and tobramycin target trough concentrations were $10-15$ and $\leq 1 \mathrm{mg} / \mathrm{L}$, respectively. Target gentamicin trough and peak concentrations were $<1$ and $8-12 \mathrm{mg} / \mathrm{L}$, respectively.

Results In total, 482 patients were included (vancomycin [PICU] $n=62$, [NICU] $n=102$; gentamicin [NICU] $n=97$; tobramycin [NICU] $n=221$ ). Overall, median trough concentrations were within the target range for all cohorts but showed large interindividual variability, causing nontarget attainment. Trough concentrations were outside the target range in $66.1 \%$, $60.8 \%, 14.7 \%$, and $23.1 \%$ of patients in these four cohorts, respectively. Gentamicin peak concentrations were outside the range in $69 \%$ of NICU patients (term neonates $87.1 \%$, preterm infants $57.1 \%$ ). Higher creatinine concentrations were associated with higher vancomycin and tobramycin trough concentrations.

Conclusion This study illustrates the need to validate model-based dosing advice in the real-world setting as both sub-and supratherapeutic concentrations of vancomycin, gentamicin, and tobramycin were very prevalent. Our data underline the necessity for further individualization by addressing the high interindividual variability to improve target attainment.
\end{abstract}

\section{Introduction}

The Dutch Pediatric Formulary (DPF) is a national, bestevidence drug formulary that provides monographs for over 750 different drugs used in children [1]. It aims to unify

A comment on this article is available at https://doi.org/10.1007/ s40272-020-00402-6.

Electronic supplementary material The online version of this article (https://doi.org/10.1007/s40272-020-00400-8) contains supplementary material, which is available to authorized users.

Saskia N. de Wildt

Saskia.deWildt@radboudumc.nl

1 Department of Pharmacology and Toxicology and Department of Intensive Care, Radboud Institute of Health Sciences, Radboudumc, Geert Grooteplein Zuid 10, 6525 GA Nijmegen, The Netherlands prescribing for children by providing best-evidence dosing recommendations. Over time, drug monographs in the DPF are regularly updated as new, relevant information becomes available in the literature.

Recently, multiple vancomycin, gentamicin, and tobramycin population pharmacokinetic studies have been performed in neonates and children [2-4]. These studies showed that standard doses of these antibiotics frequently led to subtherapeutic exposure in specific pediatric subgroups. Therefore,

2 Royal Dutch Pharmacists Association (KNMP), Den Haag, The Netherlands

3 Intensive Care and Department of Pediatric Surgery, Erasmus MC-Sophia Children's Hospital, University Medical Center Rotterdam, Rotterdam, The Netherlands

4 Dutch Knowledge Center Pharmacotherapy for Children, The Hague, The Netherlands 


\section{Key Points}

In 2015, age- and weight-based dosing guidelines in the Dutch Pediatric Formulary were updated for vancomycin, gentamicin, and tobramycin based on published population pharmacokinetic studies. Target attainment resulting from these model-based doses was unknown.

This study shows that both sub- and supratherapeutic concentrations of vancomycin, gentamicin, and tobramycin are frequently observed, with serum creatinine levels related to the observed variability.

Future dosing recommendations should aim to be further individualized by including relevant covariates to address the remaining interindividual variability.

the DPF updated its dosing advice for subgroups of neonates and children for these antibiotics in 2015.

One of the challenges with adapting dosing recommendations based on simulations using population pharmacokinetic models is the external validity of the guidelines. Patient selection may be biased, as certain age groups may be underrepresented, patients with certain levels of organ failure may have been excluded (e.g., renal failure), or units may be focused on specific disease states (e.g., pediatric intensive care unit [PICU] with a large proportion of post cardiac surgery patients). These patient and unit details are often not described in detail in the manuscripts. Hence, while we felt that the published model-based dosing recommendations for vancomycin, gentamicin, and tobramycin were adequately validated, there was a need for a pragmatic study to assess the adequacy of target attainment for these antibiotics in a real-life setting to ensure the changed dosing recommendations were effective and safe.

With this pilot study, we aimed to externally validate the adjusted, model-based DPF dosing guidelines for vancomycin, gentamicin, and tobramycin in critically ill neonates and children. Additionally, we explored risk factors for sub- or supratherapeutic concentrations to provide a basis for further optimization of pediatric dosing guidelines.

\section{Methods}

\subsection{Study Design}

A prospective two-center study to validate the population pharmacokinetic models and the resulting dosing recommendations was outside of the DPF's available resources, so we took a more pragmatic approach to use retrospective therapeutic drug monitoring (TDM) data in two sites to assess target attainment.

We conducted a retrospective, two-center cohort study among patients admitted to the level 3 neonatal intensive care units (NICUs) or PICUs of either Erasmus MC's Sophia Children's Hospital or Radboudumc's Amalia Children's Hospital after the dosing guidelines were altered in 2015 and up to March 2017. The Medical Ethics Review Committee of the Erasmus MC reviewed the research proposal and waived the need for formal approval of the study protocol according to the Dutch Law on Human Research. The obligation for individual informed consent was waived because of the retrospective nature of this study.

The advised dose and/or dose interval of vancomycin, tobramycin, and gentamicin were altered and posted on the DPF's open access internet platform (https://www.kinde rformularium.nl) on 23 January, 23 October, and 23 June 2015 , respectively, as shown in Table 1 . The formulary provides guidance for dose adjustment in case of renal dysfunction for children aged $>1$ month but not for younger children.

\subsection{Inclusion and Exclusion Criteria}

The electronic database of hospital admissions of both hospitals was screened for records of potential patients. All patients admitted to the NICU or PICU and who received at least one dose of vancomycin, gentamicin, or tobramycin were included in this initial screening.

Inclusion criteria were as follows: postnatal age (PNA) < 18 years; admitted to the NICU or PICU; treated with intravenous vancomycin, gentamicin, or tobramycin during ICU admission; and having at least one (steady-state) trough concentration or peak concentration determined as part of TDM.

Patients were excluded if they (1) received a dose that was not concordant with the post-2015 DPF guidelines (which was defined as a daily drug dose and dose interval that deviated $>10 \%$ from the post-2015 dosing advice shown in Table 1), (2) received oral or enteral therapy, (3) started treatment before being admitted to the ICU, (4) required extracorporeal membrane oxygenation or hemofiltration therapy during antibiotic treatment, (5) were aged $>18$ years PNA, or (6) had no accurate (steady-state) trough or peak concentration determined as part of TDM. This sixth exclusion criterion could mean patients in which no TDM sample was available at all, for example with transient clinical symptoms of infection or postsurgical antibiotic prophylaxis for which antibiotic therapy was discontinued before the first TDM sample was planned or if a vancomycin concentration was measured before steady state had been achieved. Steady state of vancomycin was defined as at least three half-lives between treatment start and blood sample, with the half-life 
Table 1 Overview of dose advice for vancomycin, gentamicin, and tobramycin in the Dutch Pediatric Formulary before and after the modelbased dose alterations in 2015

\begin{tabular}{|c|c|c|c|c|}
\hline \multirow[t]{2}{*}{ Drug and subgroup } & \multicolumn{2}{|l|}{ Before 2015} & \multicolumn{2}{|l|}{ After 2015} \\
\hline & Daily dose & Dose interval (h) & Daily dose & $\begin{array}{l}\text { Dose } \\
\text { interval } \\
\text { (h) }\end{array}$ \\
\hline \multicolumn{5}{|l|}{ Vancomycin } \\
\hline Preterm, $<7$ days PNA & $20 \mathrm{mg} / \mathrm{kg} /$ day & 12 & $20 \mathrm{mg} / \mathrm{kg} /$ day & 12 \\
\hline Preterm, $\geq 7$ days PNA & $30 \mathrm{mg} / \mathrm{kg} /$ day & 8 & $30 \mathrm{mg} / \mathrm{kg} /$ day & 8 \\
\hline Term, $<7$ days PNA & $20 \mathrm{mg} / \mathrm{kg} /$ day & 12 & $32 \mathrm{mg} / \mathrm{kg} /$ day $^{\mathrm{a}}$ & $6^{\mathrm{a}}$ \\
\hline Term, $\geq 7$ days PNA & $30 \mathrm{mg} / \mathrm{kg} /$ day & 8 & $48 \mathrm{mg} / \mathrm{kg} /$ day $^{\mathrm{a}}$ & $6^{\mathrm{a}}$ \\
\hline 1 month-18 years & $40 \mathrm{mg} / \mathrm{kg} /$ day & 8 & $60 \mathrm{mg} / \mathrm{kg} / \mathrm{day}^{\mathrm{a}}$ & $6^{\mathrm{a}}$ \\
\hline \multicolumn{5}{|l|}{ Gentamicin } \\
\hline Preterm $<32$ weeks GA, $<7$ days PNA & $4 \mathrm{mg} / \mathrm{kg} / \mathrm{dose}$ & 48 & $5 \mathrm{mg} / \mathrm{kg} / \mathrm{dose}^{\mathrm{a}}$ & 48 \\
\hline Preterm 32-37 weeks GA, $<7$ days PNA & $4 \mathrm{mg} / \mathrm{kg} / \mathrm{dose}$ & 36 & $5 \mathrm{mg} / \mathrm{kg} / \mathrm{dose}^{\mathrm{a}}$ & 36 \\
\hline Preterm, $\geq 7$ days PNA & $4 \mathrm{mg} / \mathrm{kg} / \mathrm{dose}$ & $36-48$ & $4 \mathrm{mg} / \mathrm{kg} / \mathrm{dose}$ & $24^{\mathrm{a}}$ \\
\hline Term, $<7$ days PNA & $4 \mathrm{mg} / \mathrm{kg} / \mathrm{dose}$ & 24 & $4 \mathrm{mg} / \mathrm{kg} / \mathrm{dose}$ & 24 \\
\hline Term, $\geq 7$ days PNA & $4 \mathrm{mg} / \mathrm{kg} / \mathrm{dose}$ & 24 & $4 \mathrm{mg} / \mathrm{kg} / \mathrm{dose}$ & 24 \\
\hline 1 month-18 years & $7 \mathrm{mg} / \mathrm{kg} / \mathrm{dose}$ & 24 & $7 \mathrm{mg} / \mathrm{kg} / \mathrm{dose}$ & 24 \\
\hline \multicolumn{5}{|l|}{ Tobramycin } \\
\hline Preterm $<32$ weeks $\mathrm{GA},<7$ days PNA & $4 \mathrm{mg} / \mathrm{kg} / \mathrm{dose}$ & 48 & $4 \mathrm{mg} / \mathrm{kg} / \mathrm{dose}$ & 48 \\
\hline Preterm 32-37 weeks GA, $<7$ days PNA & $4 \mathrm{mg} / \mathrm{kg} / \mathrm{dose}$ & 36 & $4 \mathrm{mg} / \mathrm{kg} / \mathrm{dose}$ & 36 \\
\hline Preterm, $\geq 7$ days PNA & $4 \mathrm{mg} / \mathrm{kg} / \mathrm{dose}$ & $36-48$ & $4 \mathrm{mg} / \mathrm{kg} / \mathrm{dose}$ & $24^{\mathrm{a}}$ \\
\hline Term, $<7$ days PNA & $4 \mathrm{mg} / \mathrm{kg} / \mathrm{dose}$ & 24 & $4 \mathrm{mg} / \mathrm{kg} / \mathrm{dose}$ & 24 \\
\hline Term, $\geq 7$ days PNA & $4 \mathrm{mg} / \mathrm{kg} / \mathrm{dose}$ & 24 & $4 \mathrm{mg} / \mathrm{kg} / \mathrm{dose}$ & 24 \\
\hline 1 month-18 years & $5-7 \mathrm{mg} / \mathrm{kg} / \mathrm{dose}$ & 24 & $5-7 \mathrm{mg} / \mathrm{kg} / \mathrm{dose}$ & 24 \\
\hline
\end{tabular}

Daily dose and dose interval before and after the dose change of 2015 for vancomycin, gentamicin, and tobramycin. Dose advice is presented for different subgroups based on PNA and GA. Patients with a GA $\geq 37$ weeks are categorized as "term" and patients with GA $<37$ weeks as "preterm" if no specific GA range is specified

GA gestational age at birth, PNA postnatal age

${ }^{a}$ Change in the recommended daily dose or dose interval after 2015

in preterms $<7$ days of PNA, preterms $\geq 7$ days PNA, term neonates, and PICU patients estimated at $12,8,6$, and $6 \mathrm{~h}$, respectively $[5,6]$.

Per patient, we included only the first steady-state trough concentration for vancomycin and the first trough and peak concentration of gentamicin and tobramycin, before TDM alterations in dose or dose interval had occurred, as concentrations determined after TDM would not reflect the target attainment of the current dose advice. We chose not to exclude patients for whom the dose advice was not altered in 2015 , e.g., preterm neonates treated with vancomycin, to truly reflect target attainment and safety of these drugs in current clinical practice.

\subsection{Data Collection}

Clinical data were retrospectively collected from electronic health records at both hospitals from 1 January 2015 up to 1 March 2017. Collected data were basic demographic characteristics, admission data, antibiotic doses and their respective date and time of administration, antibiotic plasma levels and their respective date and time of determination, and serum creatinine concentrations. For neonates, gestational age (GA) at birth and birth weight were collected. Results of validated pediatric disease severity scores (Pediatric Index of Mortality [PIM]-II, Pediatric Logistic Organ Dysfunction [PELOD], Pediatric Risk of Mortality [PRISM]-III scores within $24 \mathrm{~h}$ after ICU admission) were obtained for PICU patients only, as these disease severity scores are not validated for neonates.

Drug concentrations were analyzed using a particleenhanced turbidimetric inhibition immunoassay (Architect, Abbott Laboratories, Lake Bluff, IL, USA) for gentamicin, tobramycin, and vancomycin in the Erasmus MC. This assay has lower and upper limits of quantification of 0.2 and $40 \mathrm{mg} / \mathrm{L}$ for gentamicin and tobramycin, and 1.1 and $40 \mathrm{mg} / \mathrm{L}$ for vancomycin, respectively. In the Radboudumc, plasma concentrations were analyzed using a commercially 
available, validated immunoassay (Cobas, Roche Diagnostics $\mathrm{GmbH}$, Mannheim, Germany) with lower and upper limits of quantification of 0.4 and $10 \mathrm{mg} / \mathrm{L}, 0.33$ and $10 \mathrm{mg} / \mathrm{L}$, and 4.0 and $80 \mathrm{mg} / \mathrm{L}$ for gentamicin, tobramycin, and vancomycin, respectively.

Data cleaning was carried out in accordance with the methods proposed by Van den Broeck et al. [7], and missing variables as well as possible outliers were double checked in the hospitals' patient databases.

\subsection{Statistical Analysis}

Four cohorts were established based on the administered antibiotic and ICU type: vancomycin NICU, vancomycin PICU, gentamicin NICU, and tobramycin NICU. Patients in the vancomycin and gentamicin cohorts were divided into three subgroups (subtherapeutic, therapeutic, and supratherapeutic), whereas patients in the gentamicin and tobramycin cohorts were divided into two subgroups (safe and toxic), according to the pharmacodynamic target concentrations for efficacy and/or safety. Therapeutic pharmacodynamic targets for drug efficacy were considered as a vancomycin trough concentration of $10-15 \mathrm{mg} / \mathrm{L}$ (as a surrogate marker for the adult pharmacodynamic target of area under the plasma concentration-time curve $[\mathrm{AUC}] /$ minimum inhibitory concentration $[\mathrm{MIC}]$ ratio $>400)[8,9]$ and gentamicin peak concentration of 8-12 mg/L [10]. Tobramycin peak concentrations are not routinely performed during TDM, so a pharmacodynamic target for tobramycin efficacy was not addressed. Additionally, target trough concentrations for vancomycin, gentamicin, and tobramycin safety were $>15 \mathrm{mg} / \mathrm{L}$ and $\leq 1.0 \mathrm{mg} / \mathrm{L}$ for both aminoglycoside drugs, respectively $[10,11]$.

Descriptive data are presented as medians and interquartile ranges (IQRs), and categorical data are presented as whole numbers and percentages. Attainment of the aforementioned pharmacodynamic targets for efficacy and safety is presented as the percentage of patients within the entire cohort and in each of the dosing subgroups outlined in Table 1.

Correlations between antibiotic trough concentrations and potential covariates (creatinine, disease severity scores) were assessed with Spearman's rank correlation using GraphPad version 5.03. Serum creatinine concentrations within $24 \mathrm{~h}$ of TDM were used as a covariate for glomerular filtration rate (GFR), as vancomycin, gentamicin, and tobramycin are all predominantly excreted by glomerular filtration. Subsequently, we tested the correlation of creatinine concentrations within $24 \mathrm{~h}$ of the start of treatment to investigate whether creatinine could guide antibiotic dosing at treatment commencement. Additionally, in the vancomycin PICU cohort, we tested several validated pediatric disease severity scores (PIM-II, PELOD, PRISM-III scores) to assess the correlation of critical illness with vancomycin trough concentrations [12-14].

\section{Results}

\subsection{Patient Characteristics}

In total, 1642 patients who were screened as admitted to the NICU or PICU in either of the hospitals between January 2015 and March 2017 and received vancomycin, gentamicin, or tobramycin during their ICU admission. Of these, 1160 were excluded, mainly because no (steady-state) peak or trough concentration was available $(n=923$, mainly in the gentamicin and tobramycin cohorts) or because they received a dose not in concordance with the new dosing guidelines for patients with normal renal function, leaving 482 patients for data analysis (Fig. 1). An overview of the clinical characteristics of each cohort is shown in Table 2.

\subsection{Target Attainment}

The percentage of target attainment, arranged by drug, unit, and age group, is presented in Table 3, with a visual representation in Fig. 2a-d. All cohorts and subgroups showed significant interindividual variation, even though all patients within a subgroup received a similar daily dose and dose interval. Interindividual variation seems similar between subgroups whose dose was altered in 2015, represented by triangles in Fig. 2, compared with subgroups for which no dose alteration was recommended.

\subsubsection{Vancomycin PICU cohort}

In total, 62 patients were included in the vancomycin PICU cohort, with a median age of 0.8 years, ranging from 33 days to 17.1 years (Table 2). Median vancomycin trough concentrations $(12.5 \mathrm{mg} / \mathrm{L})$ were within the target range but showed great interindividual variation, ranging from 3.3 to $47.9 \mathrm{mg} / \mathrm{L}$ (Fig. 2a). Therapeutic trough concentrations showed a prevalence of $33.9 \%$, with 30.6 and $35.5 \%$ of patients having subtherapeutic and supratherapeutic concentrations, respectively (Fig. 2a, Table 3).

\subsubsection{Vancomycin NICU Cohort}

In total, 102 patients were included in the vancomycin NICU cohort, with the majority $(70.6 \%)$ being preterm infants (GA $<32$ weeks) (Table 2). Overall, the median trough concentration was $12.6 \mathrm{mg} / \mathrm{L}$ (range 3.2-55.6 [IQR 8.6-16.9]), with $39.2,28.4$, and $32.4 \%$ of patients having therapeutic, subtherapeutic, and supratherapeutic trough 
Fig. 1 Flowchart indicating the total number of patients, number of exclusions, reason for exclusion, total number of inclusions, and stratification among our four cohorts. ECMO extracorporeal membrane oxygenation, $M C$ medical center, $N I C U$ neonatal intensive care unit, $P I C U$ pediatric intensive care unit

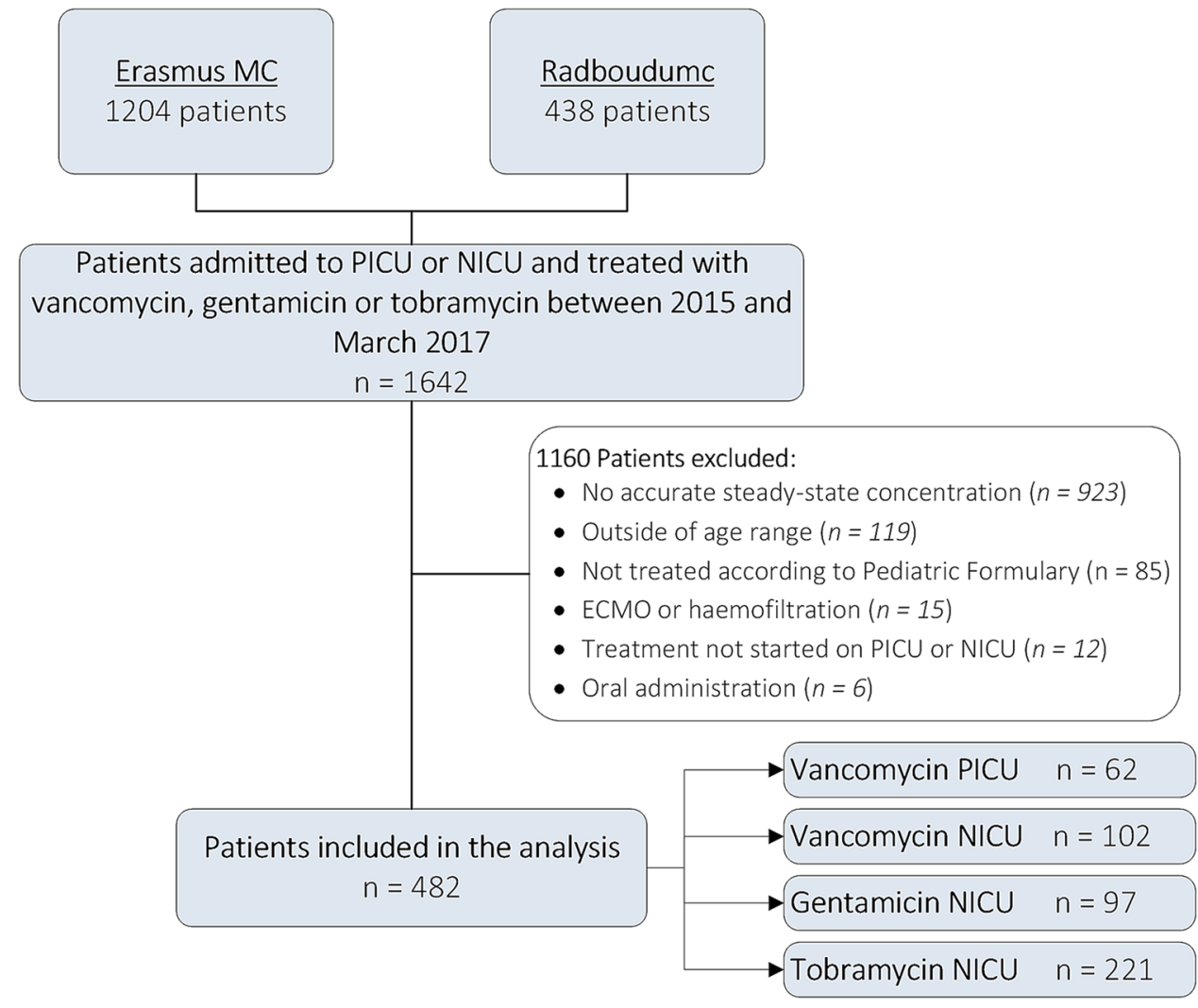

concentrations, respectively (Fig. 2b, Table 3). Term neonates aged $>1$ week showed the worst target attainment of only $10 \%$, with $90 \%$ of supratherapeutic trough concentrations $>15 \mathrm{mg} / \mathrm{L}$ (Table 3 ). In a subgroup of 36 extremely preterm neonates, aged $\leq 28$ weeks of gestation, we found a similar overall proportion of nontarget attainment $(63.9 \%)$ compared with the subgroup of 36 preterms with a GA of 28-32 weeks (58.3\%). Extremely premature neonates showed slightly more supratherapeutic drug concentrations ( 36.1 vs. $19.4 \%$ in the "older" subgroup).

\subsubsection{Gentamicin NICU cohort}

A total of 97 patients were included in the gentamicin NICU cohort, contributing 87 peak concentrations and 95 trough concentrations of gentamicin. Median gentamicin peak and trough concentrations were 7.2 and $0.8 \mathrm{mg} / \mathrm{L}$, respectively (Table 3). Gentamicin peak concentrations were mostly subtherapeutic (67.8\%) and rarely supratherapeutic (1.1\%), and the majority of trough concentrations $(85.3 \%)$ were below the toxicity threshold of $\leq 1.0 \mathrm{mg} / \mathrm{L}$ (Table 3 ). Both subtherapeutic peak concentrations and toxic trough levels were most prevalent in preterm patients $\geq 7$ days (100 and $21.4 \%$, respectively) and term patients ( $87.1 \%$ and $29.4 \%$, respectively), with both of these subgroups receiving $4 \mathrm{mg} / \mathrm{kg} / 24 \mathrm{~h}$ as opposed to $5 \mathrm{mg} / \mathrm{kg} / 36-48 \mathrm{~h}$ in preterm patients $<7$ days PNA (Table 3, Fig. 2c).

\subsubsection{Tobramycin NICU Cohort}

The 221 patients in the tobramycin NICU cohort were mostly preterm infants $(65.6 \%)$. Median tobramycin trough concentrations were $0.6 \mathrm{mg} / \mathrm{L}$, with $23.1 \%$ of samples showing toxic concentrations (Tables 2 and 3). Toxic tobramycin trough concentrations were most prevalent in patients dosed every $24 \mathrm{~h}$ (term patients [36.8\%] and preterm patients $\geq 7$ days PNA [25.4\%]) and least prevalent in preterm patients $<7$ days of PNA who are dosed every 36-48 h (2.2\% for $<32$ weeks and $14.3 \%$ for $32-37$ weeks of gestation) (Fig. 2d, Table 3). In a subgroup of 71 extreme preterms, the prevalence of toxic trough concentrations $(18.3 \%)$ was comparable to the prevalence found in 42 preterms with a higher GA of $28-32$ weeks (14.3\%).

\subsection{Correlation With Covariates}

As creatinine concentrations are not routinely checked during regular care, these data were frequently missing: 16, 48,41 , and $52 \%$ of patients had no creatinine concentration determined within $24 \mathrm{~h}$ of the TDM sample for the 
Table 2 Demographic characteristics of patients in each of the four cohorts

\begin{tabular}{|c|c|c|c|c|}
\hline Characteristics & $\begin{array}{l}\text { Vancomycin PICU } \\
(n=62)\end{array}$ & $\begin{array}{l}\text { Vancomycin NICU } \\
(n=102)\end{array}$ & $\begin{array}{l}\text { Gentamicin NICU } \\
(n=97)\end{array}$ & $\begin{array}{l}\text { Tobramycin NICU } \\
(n=221)\end{array}$ \\
\hline PNA at treatment start & 0.8 years $(0.3-8.6)$ & 8.0 days $(6.0-13.3)$ & 1.0 days $(0.0-3.0)$ & 3.0 days $(2.0-9.0)$ \\
\hline PNA $<7$ days & $0(0)$ & $27(26.5)$ & $81(83.5)$ & $146(66.1)$ \\
\hline PNA $\geq 7$ days & $62(100)$ & $75(73.5)$ & $16(16.5)$ & 75 (33.9) \\
\hline GA at birth & $-^{\mathrm{a}}$ & $\begin{array}{l}29.0 \text { weeks }(27.0-34.1) \\
{[23.9-42.3]}\end{array}$ & $\begin{array}{l}31.7 \text { weeks }(28.5-38.6) \\
{[23.9-41.9]}\end{array}$ & $\begin{array}{l}31.4 \text { weeks }(27.0-38.3) \\
{[24.0-41.9]}\end{array}$ \\
\hline$<32$ weeks & $-^{\mathrm{a}}$ & $72(70.6)$ & $50(51.5)$ & $113(51.1)$ \\
\hline $32-37$ weeks & $--^{\mathrm{a}}$ & $10(9.8)$ & $12(12.4)$ & $32(14.5)$ \\
\hline$\geq 37$ weeks & $-{ }^{\mathrm{a}}$ & $20(19.6)$ & $35(36.1)$ & $76(34.4)$ \\
\hline Weight (kg) & $8.1(5.0-30.1)$ & $1.2(0.9-2.1)$ & $1.7(1.2-3.2)$ & $1.6(1.0-3.1)$ \\
\hline Male & $31(50)$ & $61(59.8)$ & $53(54.6)$ & $138(62.4)$ \\
\hline ICU mortality & $6(9.7)$ & $7(6.9)$ & $5(5.2)$ & $35(15.8)$ \\
\hline $\begin{array}{l}\text { Duration of ICU admission } \\
\text { (days) }\end{array}$ & $17.5(6.0-41.5)$ & $19.5(10.0-44.3)$ & $12(4.0-24.5)$ & $15.6(6.5-44.7)$ \\
\hline PRISM-III score & $15(8-21)$ & $--^{\mathrm{a}}$ & $--^{\mathrm{a}}$ & $--^{\mathrm{a}}$ \\
\hline $\begin{array}{l}\text { PIM-II expected mortal- } \\
\text { ity }(\%)\end{array}$ & $1.9 \%(0.9-3.4)$ & $-{ }^{\mathrm{a}}$ & $--^{\mathrm{a}}$ & $--^{\mathrm{a}}$ \\
\hline PELOD score & $6.0(2.5-9)$, missing $=1$ & $-{ }^{\mathrm{a}}$ & $--^{\mathrm{a}}$ & $--^{\mathrm{a}}$ \\
\hline $\begin{array}{l}\text { Creatinine concentration at } \\
\text { start of antibiotic treat- } \\
\text { ment }\end{array}$ & $\begin{array}{l}34.5 \mu \mathrm{mol} / \mathrm{L}(20-53), \text { miss- } \\
\quad \text { ing }=8\end{array}$ & $\begin{array}{l}48 \mu \mathrm{mol} / \mathrm{L}(32-61), \text { miss- } \\
\quad \text { ing }=47\end{array}$ & $\begin{array}{l}70 \mu \mathrm{mol} / \mathrm{L}(64-80), \text { miss- } \\
\text { ing }=60\end{array}$ & $\begin{array}{l}71 \mu \mathrm{mol} / \mathrm{L}(60-90) \\
\text { missing }=159\end{array}$ \\
\hline $\begin{array}{l}\text { Creatinine concentration at } \\
\text { TDM }\end{array}$ & $\begin{array}{l}29 \mu \mathrm{mol} / \mathrm{L}(19-52), \text { miss- } \\
\text { ing }=10\end{array}$ & $\begin{array}{l}39 \mu \mathrm{mol} / \mathrm{L}(32-59), \text { miss- } \\
\text { ing }=49\end{array}$ & $\begin{array}{l}64 \mu \mathrm{mol} / \mathrm{L}(47-71), \text { miss- } \\
\text { ing }=40\end{array}$ & $\begin{array}{l}65 \mu \mathrm{mol} / \mathrm{L}(49-82) \\
\text { missing }=116\end{array}$ \\
\hline $\begin{array}{l}\text { Antibiotic trough concen- } \\
\text { tration }(\mathrm{mg} / \mathrm{L})\end{array}$ & $12.5(8.8-20.7)$ & $12.6(8.6-17.0)$ & $0.8(0.6-0.8)$ & $0.6(0.3-1.0)$ \\
\hline $\begin{array}{l}\text { Antibiotic peak concentra- } \\
\text { tion }\end{array}$ & $-^{\mathrm{a}}$ & $--^{\mathrm{a}}$ & $7.2 \mathrm{mg} / \mathrm{L}(6.1-8.1)$ & $--^{\mathrm{a}}$ \\
\hline
\end{tabular}

Numbers are presented as median (IQR) [range] or $n(\%)$

GA gestational age, ICU intensive care unit, NICU neonatal intensive care unit, PELOD Pediatric Logistic Organ Dysfunction, PICU pediatric intensive care unit, PIM Pediatric Index of Mortality, PNA postnatal age, PRISM Pediatric Risk of Mortality, TDM therapeutic drug monitoring

${ }^{a}$ Data not collected in this cohort

vancomycin PICU, vancomycin NICU, gentamicin NICU, and tobramycin NICU cohort, respectively (Table 1).

The relationship between creatinine at the start of treatment and drug concentrations at steady state was statistically significant for vancomycin in NICU and PICU cohorts and for tobramycin (Spearman's rho 0.427, 0.441, and 0.281, respectively; $p=0.0011,0.0008$, and 0.0407) (Fig. 3a, b, and $\mathrm{d}$, respectively). Creatinine concentrations on the day of TDM and antibiotic trough concentrations were also correlated for vancomycin in both the NICU and the PICU cohort and for tobramycin (Spearman's rho 0.502, 0.520, and 0.541, respectively; $p<0.0001$ ) (Fig. 3e, f, and h, respectively). In contrast, gentamicin trough concentrations showed no statistically significant correlation with creatinine concentrations at the start of treatment (Spearman's rho 0.219; $p=0.102$ ) or on the day of TDM (Spearman's rho $0.200 ; p=0.235$ ) (Fig. 3c and g, respectively).

In the vancomycin PICU cohort, trough concentrations were correlated with two of the three tested disease severity scores. Statistically significant correlation coefficients were seen for the PIM-II score (Spearman's rho $0.323 ; p=0.011$ ) and PELOD scores (Spearman's rho 0.256; $p=0.047$ ) but not for PRISM-III scores (Spearman's rho 0.060; $p=0.646$ ) (Fig. 1 in the electronic supplementary material, panels A, $\mathrm{B}$, and $\mathrm{C}$, respectively).

\section{Discussion}

In this retrospective two-center cohort study, we investigated the target attainment of three antibiotic agents in critically ill neonates and children after a nationwide model-based dosing guideline change. Overall, median concentrations of the studied drugs fell within the nontoxic, therapeutic range for all cohorts. However, because of the large interindividual variability seen in this patient population, a significant proportion of patients showed supra- and subtherapeutic drug levels of vancomycin, gentamicin, and tobramycin. This 
Table 3 Overview of efficacy and safety target attainment of vancomycin, gentamicin, and tobramycin in each cohort

\begin{tabular}{|c|c|c|c|}
\hline Efficacy & Subtherapeutic & Therapeutic & Supratherapeutic \\
\hline Vancomycin PICU (total) $(n=62)$ & $19(30.6)$ & $21(33.9)$ & $22(35.5)$ \\
\hline Vancomycin NICU (total) $(n=102)$ & $29(28.4)$ & $40(39.2)$ & $33(32.4)$ \\
\hline Preterm GA $+<7$ days PNA $(n=17)$ & $7(41.2)$ & $6(35.3)$ & $4(23.5)$ \\
\hline Preterm GA $+\geq 7$ days PNA $(n=65)$ & $20(30.8)$ & $28(43.1)$ & $17(26.2)$ \\
\hline Term GA $+<7$ days PNA $(n=10)$ & $2(20.0)$ & $5(50.0)$ & $3(30.0)$ \\
\hline Term GA $+\geq 7$ days PNA $(n=10)$ & $\mathbf{0}(\mathbf{0 . 0})$ & $1(\mathbf{1 0 . 0})$ & $9(90.0)$ \\
\hline Gentamicin NICU (total) $(n=87)^{\mathrm{a}}$ & $59(67.8)$ & $27(31.0)$ & $1(1.1)$ \\
\hline$<32$ weeks GA $+<7$ days PNA $(\mathrm{n}=36)^{\mathrm{a}}$ & $16(44.4)$ & $20(55.6)$ & $\mathbf{0}(\mathbf{0 . 0})$ \\
\hline$<32$ weeks GA $+\geq 7$ days PNA $(n=9)^{\mathrm{a}}$ & $9(100.0)$ & $\mathbf{0}(\mathbf{0 . 0})$ & $\mathbf{0}(\mathbf{0 . 0})$ \\
\hline 32-37 weeks GA $+<7$ days PNA $(n=9)^{a}$ & $5(55.6)$ & $3(33.3)$ & $1(11.1)$ \\
\hline 32-37 weeks $G A+\geq 7$ days PNA $(n=2)$ & $2(100.0)$ & $\mathbf{0}(\mathbf{0 . 0})$ & $\mathbf{0}(\mathbf{0 . 0})$ \\
\hline Term GA + any PNA $(n=31)^{\mathrm{a}}$ & $27(87.1)$ & $4(12.9)$ & $0(0.0)$ \\
\hline Safety & - & Safe & Toxic \\
\hline Gentamicin NICU (total) $(n=95)^{\mathrm{a}}$ & - & $81(85.3)$ & $14(14.7)$ \\
\hline$<32$ weeks GA $+<7$ days PNA $(n=38)$ & - & $38(100.0)$ & $\mathbf{0}(\mathbf{0 . 0})$ \\
\hline$<32$ weeks $G A+\geq 7$ days PNA $(n=12)$ & - & $9(75.0)$ & $3(25.0)$ \\
\hline 32-37 weeks GA $+<7$ days PNA $(n=9)^{a}$ & - & $8(88.9)$ & 1/9 (11.1) \\
\hline 32-37 weeks GA $+\geq 7$ days PNA $(n=2)$ & - & $2(100.0)$ & $\mathbf{0}(\mathbf{0 . 0})$ \\
\hline Term GA + any PNA $(n=34)^{\mathrm{a}}$ & - & 24 (70.6) & $10(29.4)$ \\
\hline Tobramycin NICU (total) $(n=221)$ & - & $170(76.9)$ & $51(23.1)$ \\
\hline$<32$ weeks GA $+<7$ days PNA $(n=46)$ & - & $45(97.8)$ & $1(2.2)$ \\
\hline $32-37$ weeks $\mathrm{GA}+<7$ days PNA $(n=28)$ & - & $24(85.7)$ & $4(14.3)$ \\
\hline Term GA + any PNA $(n=76)$ & - & $48(63.2)$ & $28(36.8)$ \\
\hline Preterm GA $+\geq 7$ days PNA $(n=71)$ & - & $53(74.6)$ & $18(25.4)$ \\
\hline
\end{tabular}

Data are presented as $n(\%)$. Target attainment for vancomycin, gentamicin, and tobramycin in the four different cohorts. Therapeutic concentrations were defined as a vancomycin trough concentration of $10-15 \mathrm{mg} / \mathrm{L}$ and gentamicin peak concentration of 8-12 $\mathrm{mg} / \mathrm{L}$. Safety for gentamicin and tobramycin was defined as trough concentrations $\leq 1 \mathrm{mg} / \mathrm{L}$. Patients with a GA $\geq 37$ weeks are categorized as "term" and patients with GA $<37$ weeks as "preterm" if no specific GA range was specified. Boldface text represents patient subgroups for which the dose advice was altered in 2015. Plain text represents groups for which no alteration in dose or dose interval was made

$G A$ gestational age, NICU neonatal intensive care unit, $P I C U$ pediatric intensive care unit, $P N A$ postnatal age

${ }^{a} n$ deviates from number of patients in the total cohort or subgroups because of missing data of peak or trough concentrations

shows that the pharmacokinetic models used for generating the dose advice accurately simulated overall concentrations but did not fully address the sources of variability in critically ill neonates and children. Surprisingly, target attainment was worst for term neonates and preterm neonates older than 1 week of PNA, with both groups showing the highest percentage of nontherapeutic peak concentrations and/or potentially toxic trough concentrations for all three drugs. Serum creatinine concentrations correlated moderately well with drug concentrations at the time of dosing and at sampling for vancomycin and tobramycin, which could be used for further optimization and individualization of dosing recommendations.

Reduced target attainment of antibiotics is common in critically ill neonates and children. Other studies that used population, dose, dose interval, and pharmacodynamic targets relatively similar to those in our study found similar results for vancomycin $[15,16]$ and gentamicin [17]. De Cock et al. [15] showed an even lower target attainment of vancomycin in PICU patients of only $8 \%$ compared with our $33.9 \%$. In critically ill neonates, overall target attainment of vancomycin was also lower (23 vs. our 39\%) in the study by Koedood et al. [16], with a slightly higher proportion of subtherapeutic concentrations (43 vs. our $28.4 \%$ ). In another study, gentamicin peak concentrations did not reach therapeutic concentrations in $>50 \%$ of neonates receiving a dose of $4-5 \mathrm{mg} / \mathrm{kg}$ [17]. The same authors also showed a high proportion of trough concentrations $\geq 1.0 \mathrm{mg} / \mathrm{L}$ in neonates aged $>7$ days who receive a single daily dose of gentamicin (20\%) [17].

The current drug dosing guidelines of the DPF seem to overestimate average clearance of term neonates and preterm neonates aged $>1$ week, as is shown by the large proportion of high trough concentrations of vancomycin, gentamicin, 
Fig. 2 Concentrations of vancomycin, gentamicin, and tobramycin in critically ill neonates and children. Overview of (steady-state) concentrations of vancomycin, gentamicin, and tobramycin concentrations in four cohorts. a Vancomycin NICU, b vancomycin PICU, c gentamicin NICU, and d tobramycin NICU cohorts. Upward facing triangles represent patient subgroups for which the dose advice was altered in 2015, open circles represent subgroups for which no alteration in dose or dose interval was made. Blue symbols represent a single-patient trough concentration, red symbols represent gentamicin peak concentrations. Dashed lines indicate the target concentrations. NICU neonatal intensive care unit, $P I C U$ pediatric intensive care unit
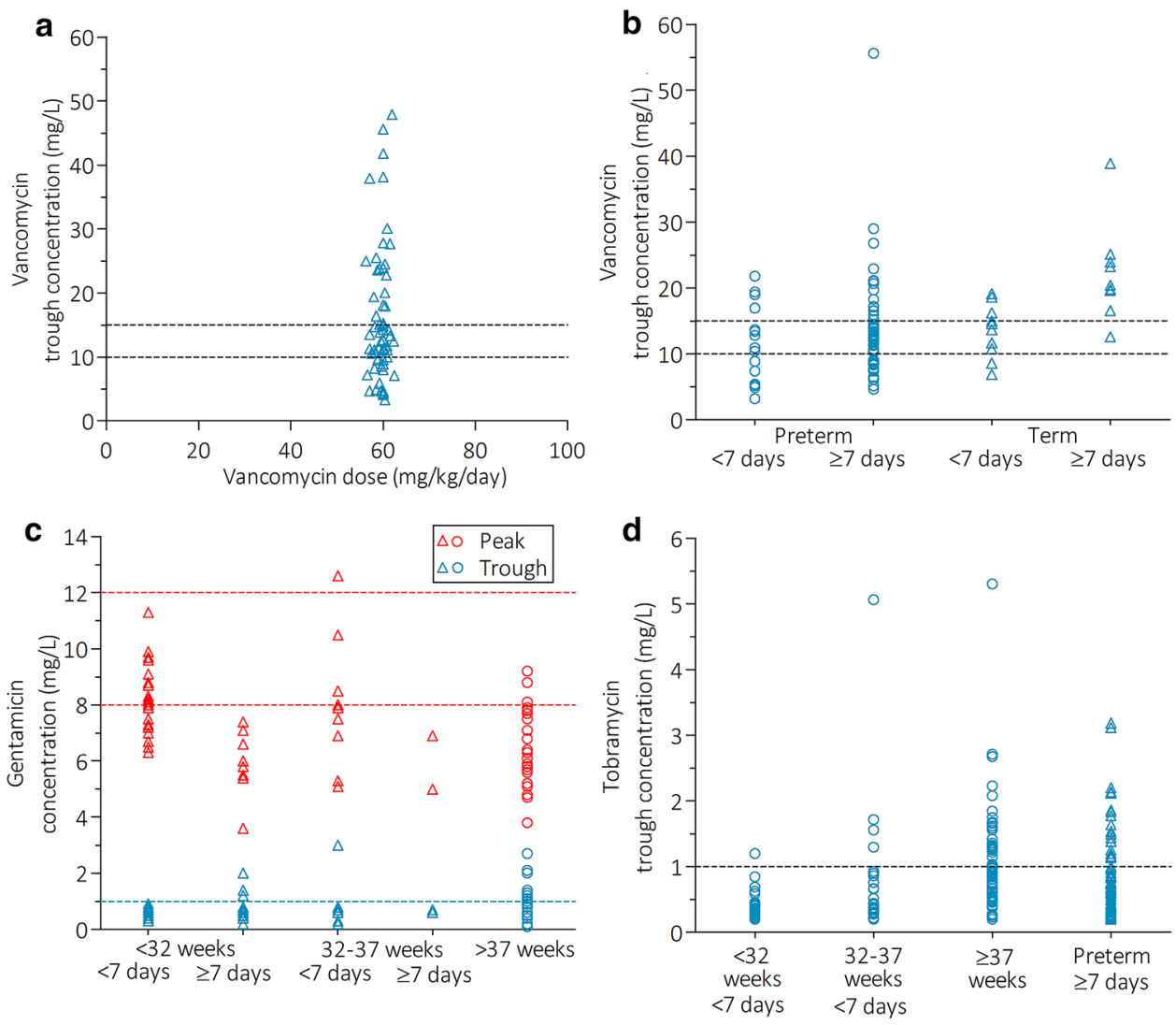

Gentamicin

Tobramycin

Vancomycin

NICU
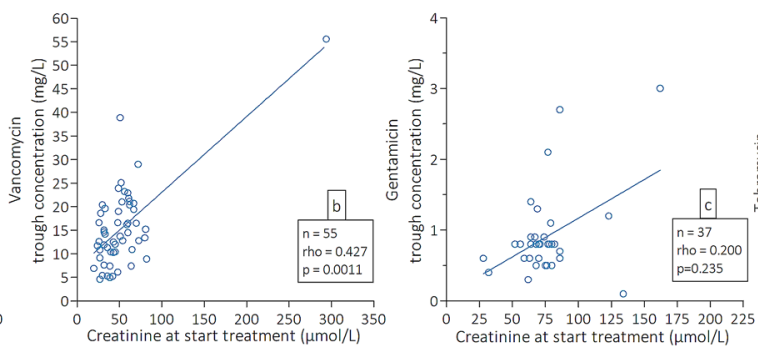

$\mathrm{NICU}$

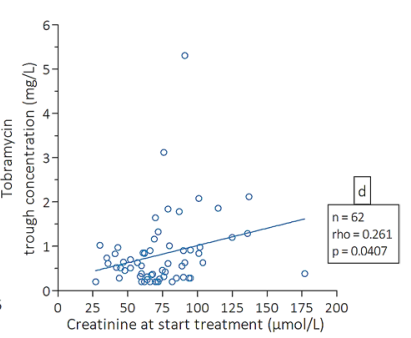

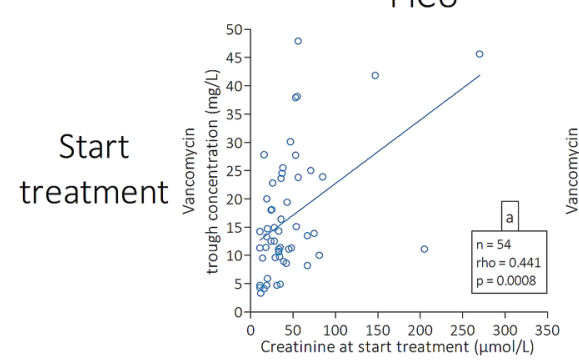
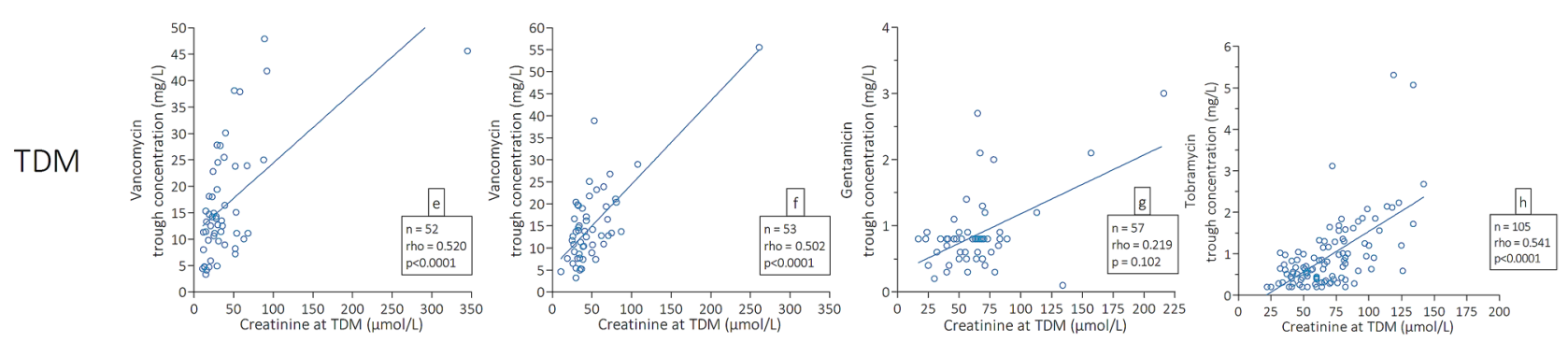

Fig. 3 Correlation of antibiotics trough concentrations with creatinine concentrations at start of antibiotic treatment and on the day of TDM. Correlation of antibiotic trough concentrations with creatinine concentrations taken within $24 \mathrm{~h}$ of start of antibiotic treatment (a-d) or within $24 \mathrm{~h}$ of the TDM sample $(\mathbf{e}-\mathbf{h})$. Open circles represent single-patient creatinine and antibiotic trough concentrations. The solid line represents the linear regression line. Correlation coefficients, $p$ values, and number of patients are presented in each panel in the corresponding legend box. Number of patients may deviate from total patient cohort because of missing creatinine data. $n$ number of patients, NICU neonatal intensive care unit, $P I C U$ pediatric intensive care unit, rho Spearman's rho correlation coefficient, TDM therapeutic drug monitoring 
and tobramycin in this study. The cause of this overestimation might lie in the studied populations on which the dose changes were based. De Cock et al. [15] used pharmacokinetic data for vancomycin, gentamicin, and tobramycin from four different studies [18-21], all including NICU and PICU patients with and without renal dysfunction but excluding patients with severe renal dysfunction. The aim of this study was to identify the impact of developmental changes of GFR on the clearance of gentamicin, tobramycin, and vancomycin. In total, over 4000 blood samples from 1760 unique patients were used to generate a semi-physiological pharmacokinetic model of this impact. The majority of patients in this study were neonates aged $<1$ month (1428 patients, $81 \%$ ), with a gestational age ranging from 23 to 43 weeks. In total, 180,95 , and 57 patients aged 1 month- 2 years, 2-11 years, and 12-18 years, respectively, completed the study cohort. Their model describes the maturation in GFR from neonates to adults using a bodyweight-dependent exponent that is similar for all three studied drugs and can be used for subsequent pharmacokinetic modeling and simulation studies. Subsequent studies by Janssen et al. [3] and Valitalo et al. [4] aimed to validate these findings and to generate model-based dosing advice for the whole pediatric age range but in their external validation did not use a "new" external dataset [4] and/or performed drug exposure simulations only for patients with normal renal function [3, 4]. As this dosing advice is applied nationwide, and for critically ill neonates and children with highly varying renal function, this creates a discrepancy between the modeled population and the actual population.

Additionally, our data on gentamicin peak concentrations suggested that the majority of concentrations were subtherapeutic, with term neonates and preterm neonates aged $\geq 7$ days showing the lowest target attainment. This could be because Valitalo et al. [4] modeled for target peak concentrations of 5-12 $\mathrm{mg} / \mathrm{L}$, whereas we defined a target peak concentration of $8-12 \mathrm{mg} / \mathrm{L}$ based on current national guidelines [10]. This higher target concentration in our study was based on literature of the pharmacodynamic targets for aminoglycoside antibiotics, wherefor the maximum effectiveness of the drug is reached when peak concentrations are six to eight times higher than the MIC of the micro-organism. This discrepancy shows another challenge when extrapolating dosing recommendations. Not only may patient characteristics differ but pharmacodynamic endpoints are also a factor for consideration.

The most prevalent Gram-negative pathogen in earlyonset neonatal sepsis is Escherichia coli [22], which has MICs of $1-2 \mathrm{mg} / \mathrm{L}$ according to the EUCAST database [23]. Hence, peak concentrations of gentamicin of at least $8-12 \mathrm{mg} / \mathrm{L}$ are needed to acquire the desired exposure. Whether these higher target concentrations as proposed in the new Dutch treatment guideline are warranted for every patient is debatable, as these pharmacodynamic targets are mostly defined in vitro, in animal or adult studies and might not apply to the NICU setting, where empirical treatment and combination therapy of broad-spectrum antibiotics is more prevalent [24].

The observed wide interindividual variability in antibiotic plasma concentrations in patients using the same weightcorrected dose is a common finding among studies in critically ill children and neonates $[18,25]$. This study shows that a linear dose alteration (e.g., vancomycin in children aged $>1$ month increased from 40 to $60 \mathrm{mg} / \mathrm{kg} /$ day) does not address this issue, as it only increases average plasma concentrations but does not account for interindividual variability because of factors other than weight, such as renal function.

Renal dysfunction is acknowledged as an important factor warranting vancomycin and aminoglycoside dose adjustment. The DPF provides dosing guidance for children aged $>1$ month with renal dysfunction, although these patients were not included in our current analyses. However, because such guidance is lacking for younger children, neonates with renal dysfunction may have received regular drug doses. This may have contributed to the overestimation in clearance in a substantial proportion of neonates aged $>7$ days. Interestingly, even in patients without renal dysfunction, serum creatinine correlates with drug concentrations of vancomycin [16, 26-33], gentamicin [19, 34], and tobramycin [35-37]. This warrants possibly also using creatinine concentrations to aid personalized dosing strategies for patients with normal or augmented renal clearance.

Our study has some limitations. First, it is a retrospective study using clinical data that were not specifically collected for research properties, which resulted in a relatively high percentage of missing data, for example for serum creatinine concentrations or detailed information on the current disease state of patients (e.g., septic shock) or comedication. Furthermore, this retrospective design could have introduced a selection bias, as only NICU and PICU patients who had their antibiotic concentrations measured during their ICU stay were included. Therefore, target attainment in patients treated for different indications or with less severe clinical symptoms might differ from our results. Additionally, some subgroups are relatively underrepresented in our study, such as neonates aged $\geq 7$ days within the GA groups of 32-37 weeks and term ( $n=2$ for both groups) in the gentamicin cohort. This indicates that results in another setting (e.g., other patient populations, medium care wards, or other hospitals) could differ from ours. Lastly, we investigated a selection of possible covariates (serum creatinine, age, and PICU disease severity scores), but other factors could also influence drug levels, including fluid balance or the use of nephrotoxic and/or vasopressor comedication. These additional 
covariates could also be a significant source of variability that will need to be addressed in future research.

As mentioned, the intra- and interpatient variability seen in critically ill neonates and children is large and is one of the main factors that contribute to the difficulty of dosing this heterogeneous group of patients. In recent years, pharmacokinetic modeling has become one of the main means to identify the sources of this variability in various special population subgroups that show differences in pharmacokinetic parameters (such as neonates/children, the critically ill, and patients with sepsis, obesity, or cancer). To date, pharmacokinetic models have mainly focused on addressing the impact of age and body size on drug disposition. Our data now suggest that the interplay with other factors, such as renal function and other clinical covariates, appears important to optimize dosing in (critically ill) children. Although future research should expand on this identification of relevant covariates on pharmacokinetics, it should also focus on the implementation and external validation of these models in daily clinical practice. In a 2015 Delphi study, a reporting guideline for pharmacokinetic studies, outlined the minimally included information in pharmacokinetic studies [38]. This included information in the literature, basic pharmacokinetic parameter findings, and sources of inter- and intrapatient variability. Although this guideline provides a good basis for high-quality reporting of pharmacokinetic studies, formularies such as the DPF can be aided further in the clinical implementation and external validation of these findings by providing the following additional elements in pharmacokinetic research articles: (1) a detailed overview of the studied population (including age, underlying pathologies, inclusion or exclusion of patients with renal or liver dysfunction); (2) information on the pharmacodynamic targets used for the evaluation of efficacy and toxicity, with (for antibiotics) information on the prevalence of MIC distributions that were used and a rationale for this target range; and (3) substantiated dose advice or simulations of different doses. Preferably, this would include an overview of the proportion of (simulated) patients who reach the pharmacodynamic targets formulated in point 2 . This basic information is often missing or unclear in current modeling studies, although it is needed to support informed, evidence-based dosing recommendations for special populations, leading to improved clinical implementation of research findings.

Ideally, in the future, the mathematical backbone of published pharmacokinetic models should be integrated in electronic health records to simplify finding the right dose for an individual patient. Bayesian forecasting software packages exist that provide evidence-based dosing advice for an individual patient, although integration in electronic health records remains in development $[39,40]$. In coming years, implementation of these complex pharmacokinetic models and application of deep learning algorithms to continually improve model predictions will hopefully address the variability in special populations to ensure adequate drug exposure for each individual patient.

\section{Conclusion}

In this pragmatic, retrospective study, we showed that recent, model-based dosing alterations for vancomycin, gentamicin, and tobramycin still result in substantial over- and underdosing of critically ill neonates and children. Interestingly, suboptimal concentrations were most prevalent in term neonates and preterm neonates aged $>1$ week. These findings indicate the importance of external, real-world validation of guideline changes. Future research should focus on addressing the large intra- and interpatient variability in special populations to improve exposure in this patient group and the implementation of evidence-based dosing in clinical practice.

\section{Compliance with Ethical Standards}

Funding No sources of funding were used to conduct this study or prepare this manuscript. Open Access funding was provided by the Netherlands Read and Publish (Springer Compact) agreement.

Conflict of interest Prof. Dr. de Wildt is Director of the Dutch Pediatric Knowledge Center Pharmacotherapy for Children and as such is responsible for the Dutch Pediatric Formularies and its international editions. Stan J.F. Hartman, Lynn B. Orriëns, Samanta M. Zwaag, Tim Poel, and Marika de Hoop have no conflicts of interest that are directly relevant to the content of this article.

Open Access This article is licensed under a Creative Commons Attribution-NonCommercial 4.0 International License, which permits any non-commercial use, sharing, adaptation, distribution and reproduction in any medium or format, as long as you give appropriate credit to the original author(s) and the source, provide a link to the Creative Commons licence, and indicate if changes were made. The images or other third party material in this article are included in the article's Creative Commons licence, unless indicated otherwise in a credit line to the material. If material is not included in the article's Creative Commons licence and your intended use is not permitted by statutory regulation or exceeds the permitted use, you will need to obtain permission directly from the copyright holder. To view a copy of this licence, visit http://creativecommons.org/licenses/by-nc/4.0/.

\section{References}

1. van der Zanden TM, de Wildt SN, Liem Y, Offringa M, de Hoog M, Dutch Paediatric Pharmacotherapy Expertise Network N. Developing a paediatric drug formulary for the Netherlands. Arch Dis Child. 2017;102(4):357-61.

2. De Cock RF, Allegaert K, Brussee JM, Sherwin CM, Mulla H, de Hoog M, et al. Simultaneous pharmacokinetic modeling of gentamicin, tobramycin and vancomycin clearance from neonates to adults: towards a semi-physiological function for maturation in glomerular filtration. Pharm Res. 2014;31(10):2643-54. 
3. Janssen EJ, Valitalo PA, Allegaert K, de Cock RF, Simons $\mathrm{SH}$, Sherwin CM, et al. Towards rational dosing algorithms for vancomycin in neonates and infants based on population pharmacokinetic modeling. Antimicrob Agents Chemother. 2016;60(2):1013-21.

4. Valitalo PA, van den Anker JN, Allegaert K, de Cock RF, de Hoog M, Simons SH, et al. Novel model-based dosing guidelines for gentamicin and tobramycin in preterm and term neonates. J Antimicrob Chemother. 2015;70(7):2074-7.

5. Gross JR, Kaplan SL, Kramer WG, Mason EO Jr. Vancomycin pharmacokinetics in premature infants. Pediatr Pharmacol (NY). 1985;5(1):17-22.

6. de Hoog M, Schoemaker RC, Mouton JW, van den Anker JN. Vancomycin population pharmacokinetics in neonates. Clin Pharmacol Ther. 2000;67(4):360-7.

7. Van den Broeck J, Cunningham SA, Eeckels R, Herbst K. Data cleaning: detecting, diagnosing, and editing data abnormalities. PLoS Med. 2005;2(10):e267.

8. de Hoog M, Mouton JW, van den Anker JN. Vancomycin: pharmacokinetics and administration regimens in neonates. Clin Pharmacokinet. 2004;43(7):417-40.

9. Martin JH, Norris R, Barras M, Roberts J, Morris R, Doogue M, et al. Therapeutic monitoring of vancomycin in adult patients: a consensus review of the American Society of Health-System Pharmacists, the Infectious Diseases Society of America, and the Society Of Infectious Diseases Pharmacists. Clin Biochem Rev. 2010;31(1):21-4.

10. Touw DJ, Westerman EM, Sprij AJ. Therapeutic drug monitoring of aminoglycosides in neonates. Clin Pharmacokinet. 2009;48(2):71-88.

11. Allegaert K, Flint R, Smits A. Pharmacokinetic modelling and Bayesian estimation-assisted decision tools to optimize vancomycin dosage in neonates: only one piece of the puzzle. Expert Opin Drug Metab Toxicol. 2019;15(9):735-49.

12. Slater A, Shann F, Pearson G, Paediatric Index of Mortality Study G. PIM2: a revised version of the Paediatric Index of Mortality. Intensive Care Med. 2003;29(2):278-85.

13. Leteurtre S, Martinot A, Duhamel A, Proulx F, Grandbastien B, Cotting J, et al. Validation of the paediatric logistic organ dysfunction (PELOD) score: prospective, observational, multicentre study. Lancet. 2003;362(9379):192-7.

14. Pollack MM, Patel KM, Ruttimann UE. PRISM III: an updated Pediatric Risk of Mortality score. Crit Care Med. 1996;24(5):743-52.

15. De Cock PA, Desmet S, De Jaeger A, Biarent D, Dhont E, Herck I, et al. Impact of vancomycin protein binding on target attainment in critically ill children: back to the drawing board? J Antimicrob Chemother. 2017;72(3):801-4.

16. Koedood L, De Haan TR, Hodiamont CJ, Van Haelst IMM, Mathot RAA. Evaluation of a new Dutch guideline for vancomycin dosing and population pharmacokinetics of vancomycin for preterm and term neonates. Pharm Weekbl. 2019;154(15):19-23.

17. van Donge T, Pfister M, Bielicki J, Csajka C, Rodieux F, van den Anker J, et al. Quantitative analysis of gentamicin exposure in neonates and infants calls into question its current dosing recommendations. Antimicrob Agents Chemother. 2018;62:4.

18. Anderson BJ, Allegaert K, Van den Anker JN, Cossey V, Holford $\mathrm{NH}$. Vancomycin pharmacokinetics in preterm neonates and the prediction of adult clearance. Br J Clin Pharmacol. 2007;63(1):75-84.

19. Lopez SA, Mulla H, Durward A, Tibby SM. Extended-interval gentamicin: population pharmacokinetics in pediatric critical illness. Pediatr Crit Care Med. 2010;11(2):267-74.

20. Sherwin CM, McCaffrey F, Broadbent RS, Reith DM, Medlicott NJ. Discrepancies between predicted and observed rates of intravenous gentamicin delivery for neonates. J Pharm Pharmacol. 2009;61(4):465-71.

21. de Hoog M, Schoemaker RC, Mouton JW, van den Anker JN. Tobramycin population pharmacokinetics in neonates. Clin Pharmacol Ther. 1997;62(4):392-9.

22. Zea-Vera A, Ochoa TJ. Challenges in the diagnosis and management of neonatal sepsis. J Trop Pediatr. 2015;61(1):1-13.

23. The European Committee on Antimicrobial Susceptibility Testing. Breakpoint tables for interpretation of MICs and zone diameters. Version 10.0. 2020. https://www.eucast.org.

24. de Hoog M, van den Anker JN. Therapeutic drug monitoring of aminoglycosides in neonates. Clin Pharmacokinet. 2009;48(5):343-4 (author reply 4-5).

25. Marsot A. Pharmacokinetic variability in pediatrics and intensive care: toward a personalized dosing approach. J Pharm Pharm Sci. 2018;21(1):354-62.

26. Genuini M, Oualha M, Bouazza N, Moulin F, Treluyer JM, Lesage $\mathrm{F}$, et al. Achievement of therapeutic vancomycin exposure with continuous infusion in critically ill children. Pediatr Crit Care Med. 2018;19(6):e263-9.

27. Holsen MR, Meaney CJ, Hassinger AB, Fusco NM. Increased risk of acute kidney injury in critically ill children treated with vancomycin and piperacillin/tazobactam. Pediatr Crit Care Med. 2017;18(12):e585-91.

28. Moffett BS, Resendiz K, Morris J, Akcan-Arikan A, Checchia PA. Population pharmacokinetics of vancomycin in the pediatric cardiac surgical population. J Pediatric Pharmacol Therapeutics. 2019;24(2):107-16.

29. Silva DC, Seixas GT, Araujo OR, Arduini RG, Carlesse FA, Petrilli AS. Vancomycin serum concentrations in pediatric oncologic/hematologic intensive care patients. Braz J Infect Dis. 2012;16(4):361-5.

30. Thomas CA, Picone A, Menon S, Willis BC. Empirical vancomycin dosing in pediatric patients with congenital heart disease and the impact of cardiopulmonary bypass on trough concentrations. Pharmacotherapy. 2017;37(11):1341-6.

31. Zane NR, Reedy MD, Gastonguay MR, Himebauch AS, Ramsey EZ, Topjian AA, et al. A population pharmacokinetic analysis to study the effect of therapeutic hypothermia on vancomycin disposition in children resuscitated from cardiac arrest. Pediatr Crit Care Med. 2017;18(7):e290-e297297.

32. Chung E, Lee SE, Abraham T, Saad NN, Gad A. Evaluation of vancomycin target trough attainment with published dosing regimens in the neonatal intensive care unit population. J Neonatal Perinatal Med. 2019;12(1):21-7.

33. Avedissian SN, Bradley E, Zhang D, Bradley JS, Nazer LH, Tran TM, et al. Augmented renal clearance using populationbased pharmacokinetic modeling in critically ill pediatric patients. Pediatr Crit Care Med. 2017;18(9):e388-94.

34. Zakova M, Pong S, Trope A, Atenafu EG, Papaioannou V, Bitnun SA, et al. Dose derivation of once-daily dosing guidelines for gentamicin in critically ill pediatric patients. Ther Drug Monit. 2014;36(3):288-94.

35. Conil JM, Georges B, Ruiz S, Rival T, Seguin T, Cougot P, et al. Tobramycin disposition in ICU patients receiving a once daily regimen: population approach and dosage simulations. Br J Clin Pharmacol. 2011;71(1):61-71.

36. Peris-Marti JF, Borras-Blasco J, Rosique-Robles JD, Gonzalez-Delgado M. Evaluation of once daily tobramycin dosing in critically ill patients through Bayesian simulation. J Clin Pharm Ther. 2004;29(1):65-70.

37. Rea RS, Capitano B, Bies R, Bigos KL, Smith R, Lee H. Suboptimal aminoglycoside dosing in critically ill patients. Ther Drug Monit. 2008;30(6):674-81. 
38. Kanji S, Hayes M, Ling A, Shamseer L, Chant C, Edwards DJ, et al. Reporting guidelines for clinical pharmacokinetic studies: the ClinPK statement. Clin Pharmacokinet. 2015;54(7):783-95.

39. Fuchs A, Csajka C, Thoma Y, Buclin T, Widmer N. Benchmarking therapeutic drug monitoring software: a review of available computer tools. Clin Pharmacokinet. 2013;52(1):9-22.
40. Kumar AA, Burgard M, Stacey S, Sandaradura I, Lai T, Coorey $\mathrm{C}$, et al. An evaluation of the user-friendliness of Bayesian forecasting programs in a clinical setting. Br J Clin Pharmacol. 2019;85(10):2436-41. 